\title{
Avaliação da atividade antioxidante e inibição da tirosinase do extrato das folhas do jatobá (Hymenaea stigonocarpa Mart. ex Hayne)
}

\author{
MIRANDA, A.R. ${ }^{1,2}$; CASTRO, C.F.S. ${ }^{\prime}$; SILVÉRIO, M.D.O.1,2 \\ 1 Instituto Federal de Educação, Ciência e Tecnologia Goiano, Rodovia Sul Goiana, Km 01 - Zona Rural \\ Rio Verde - GO, CEP: 75901-970, aildo@fesurv.br; ' Universidade de Rio Verde - UNIRV, Fazenda Fontes do \\ Saber, Rio Verde - GO, CEP: 75900-000.
}

RESUMO: Espécies de Jatobá (Hymenaea stigonocarpa Mart. ex Hayne) são tradicionalmente utilizadas para o tratamento de diversas doenças. Estudos quimiotaxonômicos têm relacionado o gênero Hymenaea como fonte potencial de compostos fenólicos, taninos, flavonoides, os quais apresentam atividade antioxidante, sendo assim substâncias potencialmente inibidoras da tirosinase, enzima responsável por defeitos da pigmentação da pele. Existem cerca de 15 espécies no gênero Hymenaea, das quais 13 ocorrem no Brasil. Assim, este trabalho foi realizado para avaliar os fenóis, a atividade antioxidante, a capacidade de quelação dos íons cobre, e a capacidade de inibição da tirosinase do extrato das folhas da espécie $H$. Stigonocarpa. O material botânico (folhas), foi colhido nas árvores da área de cerrado de preservação ambiental do campus universitário FESURV - Universidade de Rio Verde - GO, seco em estufa de circulação forçada a $42^{\circ} \mathrm{C}$ por 2 dias, seguindo para a obtenção dos extratos hexânico e etanólico. A determinação do conteúdo fenólico realizada através do reativo Folin Ciocalteau demonstrou ser o extrato bruto etanólico (EBE) o que apresentou a maior concentração dessa classe $(235,7$ mg equivalente de ácido gálico por grama de EBE). Na avaliação da atividade captadora de radical, empregando o radical livre $\mathrm{DPPH}$, novamente o extrato etanólico demonstrou atividade antioxidante mais elevada (IC50 $=19 \pm 0,1 \mathrm{ppm})$. Para o procedimento de quelação de íons cobre, o extrato bruto etanólico não demonstrou tal capacidade. Quanto a inibição da enzima tirosinase, o extrato bruto etanólico, após 30 e 60 minutos, apresentou inibição de 38 e 48\%, respectivamente.

Palavras-chave: H. Stigonocarpa, compostos fenólicos, antioxidantes, radical livre, EROs

ABSTRACT: Determination of total phenol, antioxidant activity and inhibition by tyrosinase extract of jatobá (Hymenaea stigonocarpa Mart. ex Hayne) leaves. The jatobá species, also known as Brazilian cherry, are traditionally used for the treatment of various diseases. Chemotaxonomic studies have described the Hymenaea genus as a potential source of phenolic compounds, tannins and flavonoids, which have antioxidant activity, thus being potential inhibitors of tyrosinase, which is the enzyme responsible for skin pigmentation defects. There are approximately 15 species in the genus Hymenaea of which 13 are found in Brazil. This study was conducted to evaluate the phenols, the antioxidant activity, the ability to chelate copper ions and the ability to inhibit tyrosinase of the extract of the H. Stigonocarpa leaves. The plant material (leaves) was harvested from trees in the savannah (Brazilian Cerrado) area of environmental preservation of the FESURV campus - University of Rio Verde - state of Goiás, dried in a forced circulation oven at $42^{\circ} \mathrm{C}$ for 2 days and subjected to extraction with hexane (hexane crude extract) and extraction with absolute ethanol (ethanol crude extract). When determining the phenolic content performed with the Folin-Ciocalteu reagent, we found that the crude ethanol extract (CEE) presented the highest concentration $(235.7 \mathrm{mg}$ gallic acid equivalent per gram of CEE). In the evaluation of radical scavenging activity, using the DPPH free radical, the ethanol extract again showed higher antioxidant activity (IC50 $=19 \pm 0.1 \mathrm{ppm})$. For the procedure for chelation of copper ions, the crude ethanol extract tested showed no such ability. For the process of inhibiting the tyrosinase enzyme, the crude ethanol extract tested after 30 and 60 minutes presented inhibition of 38 and $48 \%$, respectively.

Key words: H. stigonocarpa, phenolic compounds, antioxidants, free radical, ROS. 


\section{INTRODUÇÃO}

Os radicais livres e outros oxidantes possuem papel importante no envelhecimento e em doenças degenerativas que acometem toda a população. Um radical livre pode ser um agrupamento atômico, íon ou molécula livre, que contém um ou mais elétrons desemparelhados em seu orbital mais energético. Alguns exemplos de espécies de radicais livres são: o oxigênio singlete, o radical superóxido, o radical hidroxila, o óxido nítrico, o peroxinitrito, e o radical semiquinona. Essas moléculas são instáveis e altamente reativas. A sua ativação pode causar processos traumáticos nos tecidos pelo desencadeamento de diversas cadeias de reações (Córdova \& Navas, 2000).

A ação dos compostos antioxidantes está relacionada à diminuição de eventos oxidativos através da ingestão de antioxidantes presentes em diferentes quantidades em varias frutas e vegetais. Dentre os compostos antioxidantes, destacamse os compostos fenólicos presentes nas formas livres ou complexadas (Rockenbach et al, 2008), que atuam como sequestradores de radicais livres e como quelantes de metais, alertando assim para a importância desses compostos, que podem ser utilizados em diversas patologias (Haslam, 1998).

Uma dessas patologias é a hiperpigmentação da pele, que pode ser dependente tanto de um aumento do número de melanócitos quanto da atividade melanogênica de enzimas, como a tirosinase (Okombi et al, 2006). A melanina é o pigmento responsável pela coloração da pele, possui alto peso molecular, é de coloração castanha e sua concentração determina a intensidade da coloração da pele. A tirosina é um aminoácido importante no processo biossintético da melanina. A tirosina sofre atuação enzimática da tirosinase (enzima que contém cobre, amplamente presente em mamíferos, plantas e fungos, reconhecendo muito compostos fenólicos como substrato), formando um complexo enzimático cúprico-proteico sintetizado nos ribossomos e transferido através do retículo endoplasmático para o aparelho de Golgi, sendo aglomerado em unidades envoltas por melanossomas (Miot et al, 2009).

Atualmente os pesquisadores estão em busca de novos agentes clareadores a fim de melhorar a estética e auto-estima das pessoas. Os agentes clareadores podem agir por diferentes mecanismos de ação, porém todos ligados à produção ou transferência de pigmentos, ou seja: destruição seletiva dos melanócitos; inibição da formação de melanossomas e alteração de sua estrutura; inibição da biossíntese de tirosinase e da atividade catalítica; inibição da formação de melanina; interferência no transporte dos grânulos de melanina; alteração química da melanina; degradação de melanossomas e querotinócitos (Gonchoroski \& Côrrea, 2005).

O Brasil possui cinco áreas de grande abundância de plantas nativas, estando entre elas o bioma Cerrado (Guarim Neto \& Morais, 2003), que é considerado um hotspot mundial, ou seja, área prioritária de conservação da biodiversidade (Aguiar et al, 2004). Devido a grande biodiversidade do cerrado brasileiro, os agentes podem ser encontrados e, eventualmente, usados em cosméticos e produtos farmacêuticos (Macrini et al, 2009).

O jatobá-do-cerrado (Hymenaea stigonocarpa Mart. ex Hayne), muito comum no cerrado e cerradão brasileiro é uma leguminosa arbórea pertencente à família Leguminosae e subfamília Caesalpinioideae (Macfie \& Thomson, 1988). Sua madeira pode ser utilizada na construção civil, a polpa dos frutos é farinácea, adocicada, comestível e de sabor e cheiro muito característicos, apreciada pela população nativa, apresenta elevado teor de fibra e açúcares, baixo conteúdo de lipídios, proteínas e amido (Silva et al, 1998).

Levando-se em conta a importância dos antioxidantes presentes em plantas, na prevenção de danos oxidativos causados pelos radicais livres e sua relação com a inibição da enzima tirosinase, prevenindo hiperpigmentações de pele, este trabalho visa determinar os fenóis totais, a atividade antioxidante, a capacidade de quelação dos íons cobre e a capacidade de inibição da tirosinase pelos compostos presentes na espécie Hymenaea stigonocarpa Mart. ex Hayne.

\section{MATERIAL E MÉTODOS}

Folhas de $H$. Stigonocarpa foram coletadas em Rio Verde, entre os meses de novembro a fevereiro de 2011. O material foi localizado pelo Ecologista ambiental Claudio Costa Barbosa, professor da Universidade de Rio Verde - GO, onde se encontra a área de cerrado de preservação ambiental, com as coordenadas $17^{\circ} 47^{\prime} 17.85^{\prime \prime} \mathrm{S}, 50^{\circ}$ 57’57.65"O, elevação $785 \mathrm{~m}$. As folhas de Jatobá foram identificadas no Herbário Jataiense (HJ2852).

\section{Preparo dos extratos brutos vegetais}

Após a secagem em estufa de circulação forçada a $42^{\circ} \mathrm{C}$ por dois dias, as folhas foram trituradas, dando início à extração, onde cerca de $40 \mathrm{~g}$ do pó resultante foram colocados em um erlenmayer, e adicionado um volume de cerca de $400 \mathrm{~mL}$ de hexano, permanecendo em maceração por $48 \mathrm{~h}$, à temperatura ambiente e protegida da luz. Após este período, foi feito a filtração e concentração por destilação sob pressão reduzida.

Rev. Bras. PI. Med., Campinas, v.16, n.3, supl. I, p.693-699, 2014. 
O procedimento foi repetido por mais duas vezes com o solvente hexano, obtendo-se desta forma o extrato bruto hexânico $(E B H)$ das folhas.

Em seguida, o mesmo procedimento foi repetido, utilizando-se etanol como solvente, obtendo-se o extrato bruto etanólico (EBE) das folhas. O rendimento dos extratos foi calculado pela expressão: Rendimento (\%) = (massa do extrato/ massa do material vegetal) $\times 100$.

\section{Determinação do conteúdo de compostos fenólicos}

A determinação do conteúdo de compostos fenólicos nos extratos etanólico e hexânico foi realizada baseada no método espectrofotométrico de Folin-Ciocalteau (Meda et al., 2005), com algumas modificações.

Foi preparada uma solução de $17,5 \mathrm{mg}$ de ácido gálico em $50 \mathrm{~mL}$ de etanol absoluto e diluída a seguir nas concentrações de $9 / 10 ; 8 / 10 ; 7 ; 10$; 6/10; 5/10; 4/10; 3/10; 2/10; 1/10. Em cada diluição foi adicionado $0,5 \mathrm{ml}$ do reagente de Folin, $2 \mathrm{~mL}$ de solução de bicarbonato de sódio a $15 \%$, com um período de 2 horas de incubação a temperatura ambiente e leitura em espectrofotômetro a $750 \mathrm{~nm}$, para a elaboração da curva de concentração padrão, sendo todas as leituras em triplicatas, usando o etanol absoluto como branco. Amostras de $0,1 \mathrm{~g}$ dos extratos bruto etanólico e hexânico, foram diluídas para $100 \mathrm{~mL}$ de etanol absoluto, em seguida uma segunda diluição para 5 vezes no mesmo solvente, utilizando-se $0,1 \mathrm{ml}$ das respectivas amostras para a reação com o reativo de Folin e leitura depois de incubação de 2 horas em espectrofotômetro a $750 \mathrm{~nm}$.

O teor de fenóis totais (FT) foi determinado através da curva de concentração padrão e expresso como mg de EAG (equivalentes de acido gálico) por $g$ de extrato.

\section{Avaliação da atividade antioxidante}

A ação antioxidante da $H$. Stigonocarpa foi analisada pela capacidade dos antioxidantes presentes na amostra captarem o radical livre DPPH (2,2 - difenil - 1 - picrilhidrazina), conforme a metodologia descrita por Melo et al. (2006), e controle com BHT (ButilHidroxiTolueno). Para a avaliação da atividade captadora do radical livre DPPH, alíquotas de 0,$2 ; 0,4 ; 0,6 ; 0,8$ e $1,0 \mathrm{~mL}$ dos extratos brutos etanólicos e hexânicos, na concentração de 20 mg.L ${ }^{1}$, reagiram com $4 \mathrm{~mL}$ de DPPH na concentração de $2 \mathrm{mg}^{\mathrm{L}-1}$, tendo como solvente etanol absoluto. Em seguida foi feito a leitura no espectrofotômetro a $517 \mathrm{~nm}$ em triplicata, com 30 minutos de incubação. O desconto da coloração do extrato bruto etanólico e extrato bruto hexânico (compensação), foi feito com a diluição das respectivas alíquotas em etanol absoluto, perfazendo um volume total de $5 \mathrm{ml}$, com leitura em espectrofotômetro a $517 \mathrm{~nm}$.

Para avaliar a atividade captadora de radical, foi obtida a porcentagem de inibição, conforme a equação:

$$
\% \text { DPPHseq }=\frac{\text { Abs }(\text { Controle })-[\text { Abs }(\text { amostra })-\text { Abs }(\text { compensação }]}{\text { Abs }(\text { Controle })} \times 100
$$

Os dados obtidos foram usados para construir curvas de DPPH sequestrado versus a concentração da amostra, de modo a determinar a Concentração Efetiva 50 (CE50), ou seja, a concentração necessária para sequestrar metade do teor inicial de DPPH através da análise de regressão linear e interpolação dos mesmos.

Todas as medidas foram realizadas em três experimentos independentes, cada um em triplicata, e os resultados foram expressos em mg.L-1 como média e desvio padrão.

\section{cúprico $\mathrm{Cu}^{2+}$ \\ Procedimento para quelação de íons \\ Conforme descrito por Khatib (2005)} com adaptações em nosso laboratório, para o procedimento de quelação de íons cobre $\left(\mathrm{Cu}^{2+}\right)$, preparou-se as seguintes soluções: padrão de ácido Kójico (1000 ppm), solução de ácido Etilenodiaminotetracético (EDTA) (1000 ppm), solução tampão fostato ( $\mathrm{pH} 6,8)$, solução de sulfato cúprico pentahidratado (1000ppm) e solução do extrato bruto etanólico (EEB) das folhas de jatobá (1000 ppm). O espectrofotômetro foi ajustado para leituras de absorbância na faixa entre 260 a 500 $\mathrm{nm}$, com varredura de 5 em $5 \mathrm{~nm}$, em triplicatas utilizando-se cubetas de quartzo. Inicialmente $500 \mu \mathrm{L}$ da solução do extrato etanólico, $500 \mu \mathrm{L}$ da solução padrão de ácido kójico e $2 \mathrm{~mL}$ da solução

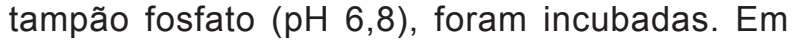
seguida realizou-se a leitura em espectrofotômetro na faixa entre 260 a $500 \mathrm{~nm}$. Após essa leitura adicionou-se $100 \mu \mathrm{L}$ da solução de sulfato cúprico pentahidratado, e realizou-se novamente a leitura na mesma faixa de absorbância e por fim adicionou-se $100 \mu \mathrm{L}$ da solução do complexante EDTA e, então novamente fez-se a leitura também na mesma faixa de absorbância, dessa forma sendo possível verificar a formação ou não de quelatos através das medidas de absorbância. 


\section{Procedimento para ensaio de inibição de tirosinase}

A enzima tirosinase de cogumelo e o substrato L-tirosina foram adquiridos da Sigma Chemical e Vetec respectivamente. A atividade da tirosinase foi determinada por espectrofotometria conforme descrito por Khatib (2005), com adaptações em nosso laboratório. A enzima tirosinase foi diluída em água destilada para $100 \mathrm{~mL}$ de solução, resultando em uma concentração de $200 \mathrm{U} / \mathrm{mL}$. As demais soluções foram: solução padrão de ácido Kójico 1000 ppm, solução de extrato etanólico (EEB) da folha de jatobá a 1000 ppm, solução tampão fosfato $\mathrm{pH}$ 6,8 e solução de L-tirosina e $2 \mathrm{mM}$. De forma geral $500 \mu \mathrm{L}$ de tampão fosfato $\mathrm{pH} 6,8,2$ $\mathrm{mL}$ da enzima tirosinase e $50 \mu \mathrm{L}$ da amostra da solução do extrato etanólico (EEB) ou sem (etanol no lugar do extrato da folha) e outra com o padrão ácido kójico, foram misturadas, obtendo-se assim 3 soluções testes separadas em triplicata. Depois de 5 minutos, adicionou-se $2 \mathrm{~mL}$ da solução $2 \mathrm{mM}$ de L-tirosina. A absorção a $475 \mathrm{~nm}$ foi monitorada em função do tempo, realizando-se duas leituras, uma em 30 minutos e outra após 60 minutos. A variação da densidade ótica foi comparada na presença e ausência dos extratos para verificar a inibição da tirosinase.

\section{Análise estatística}

Os resultados foram apresentados como médias e desvios padrão de três ensaios independentes. O programa estatístico utilizado foi o SISVAR. Dados com $p<0,05$ foram considerados significativos.

\section{RESULTADOS E DISCUSSÃO}

O gênero Hymenaea é reconhecido como fonte de compostos fenólicos (Silva, 2010; Silva, 2011), sendo que a espécie objeto deste estudo, $H$. stigonocarpa apresentou considerável quantidade destes compostos. A determinação dos conteúdos fenólicos presentes nas amostras de extrato bruto hexânico e extrato bruto etanólico, foram feitas por meio de espectrofotometria no comprimento de onda a $750 \mathrm{~nm}$, utilizando o método de Folin-Ciocalteu com modificações. O teor de fenóis totais foi determinado por interpolações da absorbância das amostras contra uma curva de calibração construída com padrões de ácido gálico e expressos como mg de EAG (equivalentes de ácido gálico) por gramas de extrato, cuja concentração de Abs $=0,0012 \mathrm{x}$ (Conc Ácido Gálico, ppm) - 0,0007, R = 0,9995.

A Tabela 1 demonstra que o extrato etanólico apresentou maior quantidade de conteúdos fenólicos em relação ao extrato hexânico.
TABELA 1. Teor de Fenóis Totais expressos em equivalentes de Ácido Gálico (EAG).

\begin{tabular}{cc}
\hline Amostra & $\begin{array}{c}\text { Fenóis totais } \\
\left.\text { (mg EAG g }{ }^{-1} \mathbf{~ m s}\right)\end{array}$ \\
\hline Extrato etanólico & $235,7 \pm 1,9 \mathrm{a}$ \\
Extrato hexânico & $166,9 \pm 4,2 \mathrm{~b}$
\end{tabular}

*ms: massa seca

Letras minúsculas iguais indicam equivalência estatística pelo SISVAR.

Ambos ao nível $5 \%$ de significância.

Para que houvesse decréscimo de $50 \%$ na concentração inicial de DPPH (CE50), foi necessário 19,1 $\pm 0,1 \mathrm{ppm}$ do extrato etanólico bruto, $60,7 \pm 0,6 \mathrm{ppm}$ do extrato hexânico bruto e $181 \pm 6 \mathrm{ppm}$ de $\mathrm{BHT}$, conforme representado na tabela 2. Isso mostra que os compostos com atividade antioxidante concentram-se no extrato bruto etanólico, ou seja, o extrato mais polar. Estudos sugerem que os melhores resultados obtidos para a atividade antioxidante pelo método do sequestro do radical livre DPPH concentram-se preferencialmente nos extratos polares (etanólico e aquoso), provavelmente tendo como constituintes polifenóis e flavonóides (Ribeiro et al, 2007). Em comparação com estudos feitos por Sousa et al. (2007), o extrato bruto etanólico das folhas de jatobá (Tabela 2), apresentou maior capacidade de sequestro do radical livre DPPH do que os extratos brutos etanólicos de folhas das plantas T. brasiliensis, C. macrophyllum, T. fagifolia e $Q$. grandiflora.

Os compostos fenólicos possuem atividade antioxidante relacionada principalmente com suas propriedades redutoras e estrutura química, que contém anel benzênico com grupos hidroxilas associado diretamente à estrutura cíclica (Mamede \& Pastore, 2004), agindo através da doação de átomos de hidrogênio ou de elétrons, o que transforma os radicais em substâncias estáveis (Silva et al, 2010). Tais características desempenham papel importante na neutralização ou sequestro de radicais livres e quelação de metais de transição, podendo agir no início ou na propagação do processo oxidativo (Sousa et al, 2007).

Ambos ao nível $5 \%$ de significância.

Diversos estudos tem identificado a presença de compostos fenólicos em várias espécies de plantas, como por exemplo, no vinho (Mamede \& Pastore, 2004), na canola (Naczk et al, 1998), no girassol (Kubicka et al, 1999), na prímula (Balasinska \& Troszynska, 1998; Wettasinghe \& Shahidi, 1999),

Rev. Bras. PI. Med., Campinas, v.16, n.3, supl. I, p.693-699, 2014. 
TABELA 2. Atividade Antioxidante dos Extratos Etanólico e Hexânico.

\begin{tabular}{lc}
\hline \multicolumn{1}{c}{ Amostra } & $\begin{array}{c}\text { Quantidade de extrato (ppm) necessária para decrescer } \\
\text { a concentração inicial de DPPH em 50\% (CE50). }\end{array}$ \\
\hline Extrato etanólico & $19,1 \pm 0,1$ a \\
Extrato hexânico & $60,7 \pm 0,6 \mathrm{~b}$ \\
BHT & $181 \pm 6 \mathrm{c}$ \\
\hline Letras minúsculas iquais indicam equivalência estatística pelo SISVAR.
\end{tabular}

Letras minúsculas iguais indicam equivalência estatística pelo SISVAR.

TABELA 3. Percentagem de ativação e inibição da enzima tirosinase.

\begin{tabular}{cccc}
\hline & $\begin{array}{c}\text { Enzima pura } \\
\text { (Ativação) }\end{array}$ & $\begin{array}{c}\text { Enzima + extrato etanólico } \\
\text { bruto folha (inibição) }\end{array}$ & $\begin{array}{c}\text { Enzima + ácido kójico } \\
\text { (inibição) }\end{array}$ \\
\hline Após 60 minutos & $100 \%$ a & $48 \%$ b & $-2 \% \mathrm{C}$
\end{tabular}

Letras minúsculas iguais indicam equivalência estatística pelo SISVAR.

Ambos ao nível $5 \%$ de significância.

na linhaça (Oomah et al, 1995) e no tremoço (Tsaliki et al, 1999), além de outros trabalhos que mostram que muitos compostos fenólicos presentes em plantas apresentam atividade inibitória da tirosinase (Sugumaran, 2002; Boissy \& Manga, 2004; Victor et al, 2004); sendo assim, o extrato escolhido para o teste de inibição da tirosinase foi o etanólico, que apresentou maiores teores de compostos fenólicos.

A tabela 3 mostra a porcentagem de ativação/inibição da tirosinase, onde a enzima pura obteve $100 \%$ de ativação após uma hora, o extrato etanólico inibiu $48 \%$ após uma hora, e o ácido kójico inibiu completamente a enzima, chegando a apresentar valores negativos.

A capacidade de quelação dos íons cobre não mostrou resultados significativos no extrato etanólico, não apresentando deslocamento dos picos máximos de absorção, enquanto que na solução de ácido kójico observou-se o descolamento do pico máximo de $270 \mathrm{~nm}$ para $310 \mathrm{~nm}$, mostrando sua capacidade de quelação de íons. O ácido kójico (5hidroxi-2hidroximetil-4 pirona) é uma substância natural produzida por fungos e bactérias, de propriedades antimicrobianas. Seu poder inibitório é do tipo incompetitivo (CHANG, 2009), ou seja, age como quelante de cobre, provocando assim a inativação da enzima tirosinase, tendo como consequência a inibição da formação da melanina. Isso mostra que a inibição da enzima apresentada no extrato etanólico das folhas não ocorre por ação de inibidores incompetitivos por quelação de cobre.

Os estudos realizados com os extratos brutos etanólico e hexânico, obtidos das folhas de jatobá do cerrado, demonstraram que os compostos fenólicos concentram-se principalmente no extrato bruto etanólico, o que explicaria a maior ação supressora do radical livre DPPH. Por se tratar de um extrato bruto etanólico, existem inúmeras substâncias que podem ser responsáveis por tal capacidade; por isso, os resultados descritos neste trabalho estimulam a continuidade dos estudos dos compostos presentes no extrato etanólico com a intenção de isolar e identificar as substâncias responsáveis pela ação antioxidante e inibidora da tirosinase presentes no jatobá.

Os dados presentes servem como referência para as futuras investigações sobre a utilização de extratos vegetais de plantas do cerrado para o tratamento de doenças relacionadas à hiperpigmentação da pele, que substituam os produtos sintéticos que estão disponíveis no mercado, os quais trazem muitos efeitos colaterais.

O bioma cerrado, com biodiversidade riquíssima em fauna e flora, vem sendo descaracterizado a passos largos, correndo-se o risco de alguma espécie vegetal ser extinta sem ao menos se conhecer o seu verdadeiro potencial fitoquímico com potencial de cura de doenças.

\section{AGRADECIMENTOS}

Os autores agradecem ao Instituto Federal de Educação, Ciência e Tecnologia Goiano Campus Rio Verde.

\section{REFERÊNCIA}

AGUIAR, L.M.S.; MACHADO R.B.; MARINHO-FILHO J. A diversidade biológica do Cerrado. In: L.M.S. Aguiar \& A. Camargo (eds.). Ecologia e caracterização do Cerrado. 2004, pp. 19-42. 
BALASINSKA, B.; TROSZYNSKA, A. Total antioxidant activity of evening primrose (Oenotheraparadoxa) cake extract measured in vitro by liposome model and murine L1210 cells. Journal of Agricultural and Food Chemistry, v. 46, p. 3558-3563, 1998.

BOISSY, R.E.; MANGA, P. On the etiology of contact/ occupational vitiligo. Pigment Cell Research. v. 17, p. 208-214, 2004.

CALDERON, J.C.; JAIMES, L.C.; HERNÁNDEZ, E.G.; VILLANOVA, B. Antioxidant capacity, phenolic content and vitamin $\mathrm{C}$ in pulp, pel and seed from 24 exotic fruits from Colombia. Food Research International, v. 44, p.2047-2053, 2010.

CHANG, TE-SHENG. An Updated Review of Tyrosinase Inhibitors. International Journal of Molecular Sciences, v.10, p.2440-2475, 2009.

CÓRDOVA, A.; NAVAS, F.J. Os radicais livres e o dano muscular produzido

pelo exercício: papel dos antioxidantes. Revista Brasileira de Medicina do Esporte, v. 6, n.5, 2000.

GONCHOROSKI, D.D.; CÔRREA, G.M. Tratamento de hipercromia pós-inflamatória com diferentes formulações clareadoras. Infarma, v.17, n. 3/4, p. 8488, 2005.

GUARIM NETO, G.; MORAIS, R.G. Recursos medicinais de espécies do cerrado de Mato Grosso: um estudo bibliográfico. Acta Botanica Brasilica, v.17, n.4, p. 561-584, 2003.

HASLAM, E. Practical Polyphenolics from structure to molecular recognition and physiological action, Cambridge University Press: Cambridge, 1998, 103p.

KHATIB, S.; NERYA, O.; MUSA, R.; SHMUEL, M.; TAMIR, S.; VAYA, J. Chalcones as potent tyrosinase inhibitors: the importance of a 2, 4-substituted resorcinol moiety. Bioorganic \& Medicinal Chemistry, v.13, p. 433-441, 2005.

KUBICKA, E.; JEDRYCHOWSKI, L.; AMAROWICZ, R. Effect of phenolic compounds extracted from sunflower seeds on native lipoxygenaseactivity. Grasas y Aceites, v. 50, p. 3206-3209, 1999.

LIMA, V.L.A.G. de; MÉLO, E.A.; MACIEL, M.I.S.; SILVA, G.S.B.; LIMA, D.E.S. Fenólicos totais e atividade antioxidante do extrato aquoso de broto de feijão-mungo (Vigna radiata L.). Revista de Nutrição, Campinas, v. 17, n. 1, p. 53-57, 2004

MACFIE, H.J.H., THOMSON, D.M.H. Preference mapping and multidimensional scaling. In: PIGGOTT, R. J. Sensory anlaysis of foods. 2 ed. New York: Elsevier Applied Science, p. 381-409, 1988.

MACRINI, D.J.; SUFFREDINII.B.; VARELLAA.D.,YOUNES RN.; OHARA M.T. Extracts from Amazonian plants have inhibitory activity against tyrosinase: an in vitro evaluation. Brazilian Journal of Pharmaceutical Sciences, v. 45, n. 2, 2009.

MAMEDE, M.E.O.; PASTORE, G.M. Compostos Fenólicos Do Vinho: Estrutura E Ação Antioxidante. Boletim do CEPPA, v. 22, n. 2, p. 233-252, 2004.

MEDA, A.; LAMIEN, C.E.; ROMITO, M.; MILLOGO, J.; NACOULMA, O.G. Determination of the total phenolic, flavonoid and proline contents in Burkina Fasan honey, as well as their radical scavenging activity. Food Chemistry, v. 91, p. 571-577, 2005.

MELO, E.A.; MACIEL, M.I.S.; LIMA, V.L.A.G.; LEAL, F.L.L.,
CAETANO A.C.S., NASCIMENTO, R.J. Capacidade antioxidante de hortaliças usualmente consumidas. Ciência e Tecnologia de Alimentos, v. 26, n.3, p. 639-644, 2006.

MIOT, L.D.B.; MIOT, H.A.; SILVA, M.G.; MARQUES, M.E.A. Fisiopatologia do melasma. Anais Brasileiros de Dermatologia, v.84, n.6, p.623-635, 2009.

NACZK, M.; AMAROVICZ, R.; SULLIVAN, A.; SHAHIDI, F. Current research development son polyphenolics of rapeseed/canola, a review. Journal of Agricultural and Food Chemistry, v. 62, p. 489-502, 1998.

OOMAH, B. D.; KENASCHUK, E. O.; MAZZA, G. Phenolic acids in flaxseed. Journal of Agricultural and Food Chemistry, v. 43, p. 2019-2026, 1995.

OKOMBI S.; RIVAL D.; BONNET S.; MARIOTTE A. M. ; PERRIERB E.; BOUMENDJEL A. Analogues of $\mathrm{N}$-hydroxycinnamoylphenalkylamides as inhibitors of human melanocyte-tyrosinase. Bioorganic \& Medicinal Chemistry Letters, v.16, n. 8, p. 22522255, 2006.

RIBEIRO S.R.; FORTES, C.C.; OLIVEIRA, S.C.C.; CASTRO, C.F.S. Avaliação da atividade antioxidante de Solanum paniculatum (Solanaceae). Arquivos de Ciência e Saúde Unipar, v. 11, n. 3, p. 179-183, 2007.

ROCKENBACH, I.I.; SILVA G.L.; RODRIGUES, E.; KUSKOSKI, E.M.; FETT, R. Influência do solvente no conteúdo total de polifenóis, antocianinas e atividade antioxidante de extratos de bagaço de uva (Vitis vinifera) variedades Tannat e Ancelota. Ciência e Tecnologia de Alimentos, v. 28, 238-244, 2008.

SILVA, M.E.G.C., OLIVEIRA, A.C.B., BATISTA, C.C.M., ARAUJO, L.C., RODRIGUES, P.S., FONTANA, A.P., ALMEIDA, J.R.G.S. Fenóis totais e atividade antioxidante in vitro de Hymenaea martiana Hayne (Fabaceae). XXI Simpósio de Plantas Medicinais do Brasil, 2010.

SILVA, M.E.G.C., OLIVEIRA, A.C.B., GUIMARAES, A.L., OLIVEIRA, A.P., SIQUEIRA FILHO, J.A., Damasceno, P.K.F., BRANCO, C.R.C., BRANCO, A., ALMEIDA, J.R.G.S. Análise por HPLC-DAD e atividade antioxidante in vitro de Hymenaea martiana Hayne (Fabaceae). III Simpósio de Plantas Medicinais do Vale do São Francisco, 2011.

SILVA, M.L.C.; COSTA, R.S.; SANTANA, A.S.; KOBLITZ M.G.B. Compostos fenólicos, carotenóides e atividade antioxidante em produtos vegetais. Semina: Ciências Agrárias, v. 31, n. 3, p. 669-682, 2010.

SILVA M.R.; SILVA, M.A.A.P.; CHANG, Y.K. Utilização Da Farinha De Jatobá (Hymenaea Stigonocarpa Mart.) na Elaboração de Biscoitos Tipo Cookie e Avaliação de Aceitação Por Testes Sensoriais Afetivos Univariados e Multivariados. Ciência e Tecnologia de Alimentos, v. 18, n.1, p. 25-34, 1998.

SOUSA, C.M.M.; SILVA, H.R.; VIEIRA-JR, G.M.; AYRES, M.C.C.; COSTA, C.L.S.; ARAÚJO, D.S.; CAVALCANTE, L.C.D.; BARROS, E.D.S.; ARAÚJO, P.B.M.; BRANDÃO, M.S.; CHAVES, M.H. Fenóis totais e atividade antioxidante de cinco plantas medicinais.

Revista Química Nova, v. 30, n. 2, p. 351-355, 2007.

SUGUMARAN, M. Comparative biochemistry of eumelanogenesis and theprotective roles of phenoloxidase and melanin in insects. Pigment Cell Research, v.15, p.2-9, 2002. 
TSALIKI, E.; LAGOURI, V.;DOXASTAKIS, G. Evaluation of the antioxidant activity of lupin seed flour and derivatives (Lupinusalbus ssp. Graecus). Food Chemistry, v. 65, p. 71-75, 1999.

VICTOR, F.C.;GELBER, J.;RAO, B.. Melasma: a review. Journal of Cutaneous Medicine and Surgery. v.8, p.97-102, 2004.

WETTASINGHE, M.;SHAHIDI, F. Evening primrose meal, a source of natural antioxidants and scavenger of hydrogen peroxide and oxygen-derived free radicals. Journal of Agricultural and Food Chemistry, v. 47, p. 1801-1812, 1999.

Rev. Bras. PI. Med., Campinas, v.16, n.3, supl. I, p.693-699, 2014. 